\title{
Correction to: Exploring the necessity of establishing a doctor of nursing practice program from experts' views: a qualitative study
}

\author{
Mozhgan Rivaz ${ }^{1 *}$, Paymaneh Shokrollahi ${ }^{2}$, Elahe Setoodegan ${ }^{3}$ and Farkhondeh Sharif ${ }^{4}$ \\ Correction to: BMC Med Educ 21, 328 (2021) \\ https://doi.org/10.1186/s12909-021-02758-w
}

Following publication of the original article [1], the authors identified an error in the \#2 affiliation.

The correct affiliation has been updated above.

Also, they would like to correct the Methods section.

The updated section is given below and the changes have been highlighted in bold typeface.

\section{Trustworthiness}

We applied four criteria proposed by Lincoln and Guba to evaluate trustworthiness, including credibility, dependability, conformability, and transferability [22]. Triangulation in the data collection and analysis, prolonged engagement ( 6 months), and maximum variance in sampling was performed to increase the data's credibility. Moreover, member checking was considered by giving some of the developed codes to the participants to assess the degree of consensus on the codes among the researchers and the participants. Parts of the transcripts, along with the extracted codes and categories, were sent to two external examiners to assess the data analysis process and provide dependability. Transferability was achieved through providing rich descriptions [22, 24].

The original article [1] has been corrected.

The original article can be found online at https://doi.org/10.1186/s12909 021-02758-w.

* Correspondence: mrivaz@sums.ac.ir

${ }^{1}$ Community Based Psychiatric Care Research Center, Department of Nursing,

School of Nursing and Midwifery, Shiraz University of Medical Sciences,

Shiraz, Iran

Full list of author information is available at the end of the article

\section{Author details}

${ }^{1}$ Community Based Psychiatric Care Research Center, Department of Nursing, School of Nursing and Midwifery, Shiraz University of Medical Sciences, Shiraz, Iran. ${ }^{2}$ School of Medical Science, Islamic Azad University- Firoozabad, Firoozabad, Iran. ${ }^{3}$ Student Research Community, Iranian Social Security Organization, Shiraz University of Medical Sciences, Clinical Supervisor of Beheshti Hospital, Shiraz, Iran. ${ }^{4}$ Community Based Psychiatric Care Research Center, Shiraz University of Medical Sciences, Shiraz, Iran.

Published online: 24 July 2021

\section{Reference}

1. Rivaz, et al. BMC Med Educ. 2021;21:328. https://doi.org/10.1186/s12909-02102758-w.

(c) The Author(s). 2021 Open Access This article is licensed under a Creative Commons Attribution 4.0 International License, which permits use, sharing, adaptation, distribution and reproduction in any medium or format, as long as you give appropriate credit to the original author(s) and the source, provide a link to the Creative Commons licence, and indicate if changes were made. The images or other third party material in this article are included in the article's Creative Commons licence, unless indicated otherwise in a credit line to the material. If material is not included in the article's Creative Commons licence and your intended use is not permitted by statutory regulation or exceeds the permitted use, you will need to obtain permission directly from the copyright holder. To view a copy of this licence, visit http://creativecommons.org/licenses/by/4.0/. The Creative Commons Public Domain Dedication waiver (http://creativecommons.org/publicdomain/zero/1.0/) applies to the data made available in this article, unless otherwise stated in a credit line to the data. 